\title{
COMENTÁRIO SOBRE O ARTIGO AGROECOLOGIA: AS COISAS EM SEU LUGAR (A AGRONOMIA BRASILEIRA VISITA A TERRA DOS DUENDES)
}

Amílcar Baiardi ${ }^{1}$

Em artigo publicado nesta revista (NAVARRO, 2013), o pesquisador Zander Navarro questiona a importância que se pretende conferir à agroecologia, que, segundo ele, não seria um modelo idôneo para a agricultura contemporânea, como pretende o discurso de seus promotores, inclusive inserido no âmbito do Estado. Desenvolvendo seus argumentos, procura uma ressignificação do conceito, mediante três enfoques críticos. A primeira crítica explora a tentativa da "agroecologia" de hegemonizar o campo da "agricultura alternativa"; a segunda analisa o esforço desta corrente para obter um estatuto de cientificidade e a terceira sugere que a agroecologia no Brasil, tem servido como instrumento político de enfrentamento ao dominante padrão técnico da denominada agricultura moderna.

Sem discordar em essência dos argumentos de Navarro no primeiro e no terceiro enfoque, mas, considerando que os mesmos estão inseridos no campo da disputa de visões de mundo, no campo da ideologia, terreno impregnado de subjetividades, este texto limitar-se-á a apreciar a segunda abordagem ou enfoque, qual seja, o de analisar se é consistente ou não, nas palavras do autor "[...] o esforço dos agroecologistas de revestirem de uma aura científica o que está sendo feito sob tal nome, concluindo, contudo, que a agroecologia não tem ainda nenhum conteúdo propriamente científico" (2013, p. 11). Isto não representa uma rejeição de debater os outros enfoques críticos, mas as limitações de espaço, sugeridas pelos editores deste periódico científico, recomenda ir por partes.

Os preceitos sobre como bem cultivar vegetais e bem criar animais, surgem, concomitantemente, à fixação do Homo sapiens sapiens no território, em sua passagem do estado de nômade para o de sediado. Com o advento de novas técnicas de plantar, cultivar e colher e criar, em torno a 3.000 a. C., a agricultura ingressa no estágio mais avançado, deixando de ser aquela tipicamente neolítica que se distribuía como pequenas manchas pelo terreno, passando a apresentar uma continuidade e uma escala maior e repercutindo, obviamente, sobre a organização urbana. Antes do ano 2000 a.C. os

\footnotetext{
${ }^{1}$ Engenheiro Agrônomo, Mestre em Desenvolvimento, Agricultura e Sociedade e Doutor em Ciências Humanas. Professor da Universidade Católica do Salvador e da Universidade Federal da Bahia.baiardi@ufba.br
} 
sumerianos, que se encontravam no auge da Idade do Bronze, praticavam a aradura com arados leves de madeira e construíam canais através dos quais realizavam a drenagem de terras paludosas e a transferência de água para terrenos férteis, introduzindo a irrigação na história do homem. Desta época até o século XVIII da nossa era o conhecimento agronômico fez avançar a agricultura com comprometimentos mínimos, quase nulos, da natureza, dada a capacidade de resiliência.

A historiografia não é categórica sobre quem, pela primeira vez, falou ou escreveu sobre a agronomia. As hipóteses de que seria Sócrates na obra Oeconomicon de Senofonte, no conhecido diálogo com Iscimaco, ou, se teria sido Mago de Cartago, em seu Tratado de Agronomia, referido por Plínio o Velho em sua Naturalis Historia, são, ambas, de difícil comprovação. Isto porque Sócrates e Mago foram contemporâneos, no século III a. C., e também porque não existe exatidão nas referências aos mesmos.

Entretanto, o suposto de que a agricultura seria uma arte que se aplicaria em perfeita harmonia com a natureza, é encontrado na quase totalidade dos agrônomos do período clássico, gregos e romanos. Este argumento tem registro nas obras de Demócrito, Crateuas, Chartrodas, Clidemo, Epicarmo, e Teofrasto, substituto de Aristóteles no seu Liceu, durante a fase grego-clássica, e por Catão, Varrão, Lucrécio, Columella e Plínio, na fase romana.

A quase totalidade destes agrônomos visava conhecimento aplicado, pois esta era a conduta dominante no período helenístico tardio, que se situa, grosso modo, entre 200 anos a. C. e início da Era Cristã. Neste período, a Escola de Alexandria funcionava como centro cultural irradiador de saberes e de métodos de como obtê-los e Epicuro se destacava pelas lições epistemológicas, valorizadoras da percepção, contrárias aos ensinamentos da Academia de Platão, que já não atraiam por serem excessivamente teóricos.

Neste paradigma de investigação visando o conhecimento útil, a "arte agronômica" resultaria das inúmeras noções adquiridas e melhoradas por meio de tentativa e erro, produzindo conclusões generalizantes acerca de classes de objetos semelhantes. Uma prática ou procedimento bem sucedido em vários casos, em uma determinada lavoura, sugeriria a consagração da mesma, dando ensejo a que fosse considerado um preceito. Vários preceitos constituiriam uma arte.

No nascimento do pensamento agronômico praticava-se o empirismo, que não se reduz à experiência. O empirismo em suas várias acepções, segundo Amsterdamski (1996), nunca se constituiu em uma teoria experimentalista.

Como ciência ou como arte, a agronomia é muito antiga e solucionou inúmeros problemas de abastecimento e segurança alimentar. O amplo arco de saber construído por esta arte contemplava técnicas que visavam manter a fertilidade do solo, utilizando-se material orgânico de origem diversa (restos de cultivos, esterco etc.), que tratavam da retirada de pedras do terreno e o seu uso para proteger o solo da erosão, que orientavam se revestir a ponta do arado de metal. Essas técnicas também recomendavam a quantidade necessária de sementes de parreira e de oliveira em terrenos pobres e ensinavam como proceder o melhoramento de pomares e rebanhos por meio de uma seleção massal. Os princípios destas e outras obras foram divulgados por Virgílio na forma de versos como em a Bucolica, enfatizando a relação harmoniosa da agricultura com a Natureza.

Inúmeros são os agrônomos medievais, como Palladio, Crescenzi e Alamanni, en- 
tre outros, e renascentistas, como Gallo, Tarello, Africo Clemente, Falcone Piacentino, Bostichi e Soderini, na Itália e Heresbach, Van der Straet, Libault e Charles Estiene na Alemanha e na França. Em suas obras, algumas delas já não escritas em Latim, evidenciavam um conhecimento agronômico avançado, resultado de observações rigorosas e de experiências, mas tendo como preocupação central garantir a associação entre a produção e a manutenção da biodiversidade e da fertilidade.

Destarte, a influência das formas de produção e de vida do campesinato medieval sobre o pensamento agronômico, período da história no qual os laços entre o homem e a natureza foram mais intensos, é definitiva e indutora de uma trajetória que alie maior eficiência produtiva com manutenção da paisagem e da fertilidade das terras. Estes preceitos, não só levaram à segunda Revolução Agrícola - a que habilitou os solos orgânicos e pesados diferentemente da Primeira Revolução que se deu nos solos leves das várzeas - como também orientaram os paradigmas produtivos sucessivos nas ciências agrárias (BAIARDI, 1997).

Fundamentos de convívio equilibrado do produtor rural com a natureza estão presentes ao longo da evolução do pensamento agronômico e todas as vertentes desse pensamento dela se beneficiaram. Análises epistemológicas no campo da filosofia e da história da ciência sugerem existir no caso das ciências agrárias, uma continuidade inequívoca do saber clássico para o saber contemporâneo. Diferentemente de outros campos do conhecimento, o modelo kuhniano de revoluções científicas não se aplica, mecanicamente, às ciências agrárias, que evoluem mais com adaptações que com rupturas, embora, à exemplo de outras áreas do conhecimento, tenham sofridos expressivas transformações com a Revolução Científica dos séculos XVII e XVIII (BAIARDI, 2008; ROSA, 1883; SALTINI, 1984).

Não é a práxis experimentalista surgida com os trabalhos de Liebig em meados do Século XIX, que remeteria à emergência das ciências agrárias, como supõem Velho e Velho (1997). Estas ciências já existiam de fato em decorrência do papel das "artes" no pensamento agronômico, entendidas como um conjunto de conhecimentos técnicos. Indubitavelmente este saber agronômico prático e técnico, prévio à Revolução Científica, contribui expressivamente na consolidação das ciências agrárias, com as quais estabelece continuidade e para as quais transfere o preceito de busca permanente de uma orgânica e espontânea vinculação da intervenção agronômica com o equilíbrio da natureza. Não obstante esta herança ou influência, os paradigmas modernos de busca incessante de maior eficiência, negligenciaram a necessidade do "diálogo" com a natureza, gerando desequilíbrios comprometedores dos ecossistemas, operando com entropia elevada sobre sistemas fechados como a natureza, na vigência da segunda lei da termodinâmica (BAIARDI, 2008; 2009).

Embora herdeiro do conhecimento milenar, o paradigma da agricultura convencional moderna tem responsabilidade no comprometimento de ecossistemas e no seu interior há muito que seus métodos vêm sendo questionados, criando, paulatinamente, condições de rupturas que gerarão outros paradigmas que não se pautem pelo reducionismo químico. É uma questão de tempo e os sinais já são evidentes. Entretanto, tudo se dará na esfera da verdadeira ciência, como as revoluções científicas que se sucedem deste o século XVII. 
Estas considerações têm o propósito de sugerir que a vertente agroecológica do pensamento agronômico não tem a primazia e nem a legitimidade única de propor uma nova aliança entre o homem e a natureza. Esta aliança, "malgrado os pontos fora da curva" é imanente ao pensamento agronômico genuíno, integra suas raízes, e estaria, em uma construção literal livre, inserida no DNA da formação agronômica.

Se ciências agrárias obtiveram ao longo da história estatuto de cientificidade, cabem as seguintes perguntas: estará a agroecologia seguindo este caminho? Propõe-se como um ramo das ciências agrárias, ou, como anunciam seus "próceres", é algo diferente, novo, não se reconhece dentro deste conjunto? Obviamente que os defensores de ser a agroecologia uma ciência, podem argumentar que princípios e preceitos propostos para a agricultura antes da Revolução Industrial, para adotar um marco temporal claro de nascimento da agronomia moderna, fazem parte das concepções agroecológicas. É possível, mas este argumento, não pode, por outro lado, negar que o edifício do saber nas ciências agrárias incorpora a cultura camponesa medieval, por excelência apresentada como sendo o modelo mais completo de produção familiar integrada com a natureza (BAIARDI, 1997).

O afastamento desta cultura é temporário e tem como causa a revolução industrial do século XVIII e as que se seguiram, até a primeira metade do século XX. Estas transformações criaram a sociedade industrial, que inverte a taxa de urbanização comparativamente à Idade Média. A população urbana passa, em menos de três séculos, de $10 \%$ para $90 \%$ da população total, exigindo da parcela que permanece no meio rural, produzir para si e para mais nove que saíram do campo, gerando desequilíbrios como a "falha metabólica", segundo Marx (BAIARDI; DULLEY, 2012).

As incessantes buscas de aumento da produtividade das diferentes lavouras, a monocultura e a industrialização da agricultura, foram respostas ao incremento e concentração do consumo nas cidades e vieram para viabilizar a civilização industrial. Isto sempre esteve claro no âmbito da comunidade de ciências agrárias, sempre preocupou e estimulou a criatividade dirigida a, sem desconstruir a eficiência da agricultura contemporânea, que cumpre inúmeras funções, conceber modelos progressivamente sustentáveis e com baixa entropia.

A preocupação com a sustentabilidade da agricultura, portanto, não é exclusiva da agroecologia e se dissemina por outras vertentes do pensamento agronômico, inclusive no âmbito do paradigma da agricultura convencional, que tem como marca o pragmatismo na solução dos problemas de abastecimento e segurança alimentar. A conquista de um estado da arte de desenvolvimento agrícola menos desorganizador da natureza, não pode ser alcançada sem uma visão multidisciplinar, amparada em conhecimentos científicos atuais, entre eles a modificação genética, que propícia cultivares menos dependentes de insumos químicos, e o desenvolvimento em escala industrial de biocidas, inseticidas e fungicidas biológicos. O apelo à sustentabilidade do planeta vem, paulatinamente, indicando a substituição das rotas tecnológicas duras ou químicas (hard path) por rotas tecnológicas brandas ou biológicas (soft path) na produção vegetal e animal, com dependência de insumos químicos cada vez menor.

A produção integrada de frutas, conhecida como PIF, a utilização crescente de inovações mecânicas e físicas e no campo da tecnologia da informação, para o controle de pragas e doenças, atestam que o paradigma da agricultura convencional químico re- 
ducionista está com os dias contados.

A agricultura, produção vegetal e animal, da sociedade pós-industrial terá um paradigma que paulatinamente se afastará agricultura convencional químico reducionista, mas não se inspirará em preceitos agroecológicos. Desta vertente, nada pode ser aproveitado, a não ser uma vaga noção do imperativo da agricultura sustentável. A produção vegetal e animal, da sociedade pós-industrial será um resultado de uma evolução nas ciências agrárias, que segue uma tendência clara de ser mais biológica, mais sistêmica e mais consorciada e sem prejuízo da eficiência em termos de rendimento físico e de qualidade (BAIARDI; MENDES; MENDES, 2010).

Para se afirmar enquanto inserida no campo da ciência, a agroecologia deve, não só buscar inspiração na história do pensamento agronômico, mas gerar evidências empíricas de eficiência equivalente na oferta de alimentos em escala compatível com as necessidades da sociedade industrial, como fez o paradigma da agricultura convencional moderna. Se não o fizer, se não demonstrar por meio do método científico capacidade de resolver problemas de abastecimento de alimentos e matérias primas em grande escala, será considerada, na melhor das hipóteses, uma seita, como destaca Navarro (2013, p. 17) ao comentar o discurso de um extensionista rural: "Agroecologia não é plantar para vender, e sim plantar para si e sua família, e para não ter que comprar produtos contaminados por agrotóxicos. Vender sim, mas vender somente o excedente [...]".

Que excedentes serão obtidos com os protocolos da agroecologia? Serão aqueles que colocam o Brasil como maior exportador de alimentos do mundo e os que garantem saldo de balança comercial? Infelizmente o pensamento agronômico vem sendo invadido, ao longo da história, pelo conhecimento denominado pré-científico ou "fabulatório". Em poucos ramos da atividade humana as crenças fantásticas, as superstições e o senso comum jogaram um papel tão relevante como no pensamento agronômico e isto ocorre não somente nos séculos anteriores ao estabelecimento da ciência experimental, como também depois. Além desta forte interferência do senso comum, a história da agronomia, ou do pensamento agronômico, revela que, malgrado esta área do conhecimento tenha elementos de validade que independem do espaço no qual os mesmos foram construídos, são as ciências agrárias profundamente marcadas por cenários, pelo local. Estes estabelecem diferenças profundas no tecido cognitivo científico, nos processos tecnológicos e na motivação social e econômica que guia a atividade daqueles que trabalham a terra.

A natureza não será preservada, ou mesmo reconstruída, por meio de retóricas e crenças, mas sim pela visão da comunidade científica, mediada pelo racionalismo crítico de Karl Popper, que estabelece os limites para o positivismo e empirismo desenfreados.

Finalizando, nada contra Gliessman (1998), quando diz "[...] Preserving the productivity of agricultural land over the long term requires sustainable food production". Se esta recomendação de preservar uma produtividade existente é acompanhada de recomendações de adoção de Multiple Cropping Systems, melhor ainda. O problema da agroecologia é que ela não dá a menor pista de como irá alcançar uma produtividade compatível com a sobrevivência da sociedade industrial, para então, a partir daí, preservá-la. Se não dá, é meramente um exercício de retórica, uma narrativa mítica, muito ao gosto da não ciência, do obscurantismo impresso no paradigma escolástico e não da ciência, como se largamente entende. 


\section{REFERÊNCIAS}

AMSTERDAMSKI, S. Empiria/experiência. Explicação, Enciclopédia Einaudi, v. 33. Lisboa: Imprensa Nacional - Casa da Moeda, 1996.

BAIARDI, A. mudanças técnicas na agricultura medieval e o processo de transição para o capitalismo. Cadernos de Ciência e Tecnologia, v. 14, n. 3, set./dez. Brasília: 1997.

A evolução das ciências agrárias nos momentos epistemológicos da civilização ocidental. In: MARTINS, R. A. et al. Filosofia e História da Ciência do Cone Sul. $3^{\circ}$ Encontro. Campinas: AFHIC, 2008.

Prefácio. In: OLIVER, G. S. Institucionalização das ciências agrícolas e seu ensino

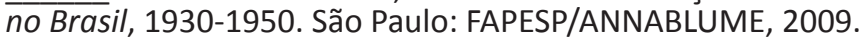

BAIARDI, A., MENDES, F., MENDES, J. Agricultura Sustentável e Biotecnologia: Reflexões Sobre a Política Agrícola e Para a Política de Ciência In: XLVIII Congresso da SOBER, 2010, Campo Grande, Anais do XLVIII Congresso da SOBER. Brasília: SOBER, 2010. v. 1. p. $321-331$

BAIARDI, A., DULLEY, R. D. Da Falha Metabólica à Nanotecnologia, o Pensamento Progressista em Relação à Organização Produtiva e à Mudança Técnica na Agricultura. Políticas Públicas, Agricultura e Meio Ambiente, Ilhéus: SOBER UESC, 2012, v. 1, p. 562-583.

GLIESSMAN, S. R. Agroecology and Sustainability. INTECOL Symposium 8. 2 July, Florence, Italy, 1998.

NAVARRO, Z. Agroecologia: as coisas em seu lugar (a Agronomia brasileira visita a terra dos duendes). Colóquio - Revista do Desenvolvimento Regional - Faccat , Taquara, v. 10, n. 1, jan./jun. 2013.

ROSA, G. Storia dell'agricoltora nella civilità. Bologna: Forni, 1883.

SALTINI, A. Storia delle scienze agrarie. Bologna: Edagricole, 1984.

VELHO, L.; VELHO, P. The emergence and institutionalization of agricultural science. Cadernos de Ciência e Tecnologia, v. 14, n. 2 maio/ago. Brasília: 1997. 